\title{
Jó 14,13-17: uma resposta à Palavra de Deus
}

\section{Job 14:13-17: a response to the Word of God}

\author{
Ednéa Martins Ornella
}

\section{Resumo}

Com a redação de Jó 14,13-17 considerada do século V a. C., analisamos o contexto histórico, econômico, social e religioso em que foi redigida, as implicações para a vida do povo de Israel e o significado teológico da poesia. Buscamos estabelecer o que motivou Jó a desejar esconder-se no sheol, por tempo determinado, até YHWH desistir de sua ira e voltar a se recordar dele. A concepção da doutrina da retribuição da época se mostrava incompatível com o sofrimento do justo e fiel, vítima da crise social que degradava o pobre cada vez mais. A classe alta espiritualizada foi chamada a dar uma resposta à Palavra de YHWH que ama os pobres. Este estudo lembra que a prática da lectio divina do passado deveria se repetir no presente, desde que se permita que o texto ultrapasse nossos próprios pensamentos e nos sensibilize de forma pessoal e comunitária para uma resposta à Palavra divina, através de uma atitude cristã diante do sofrimento humano.

Palavras-chave: Livro de Jó; Redenção; Reconciliação; Salvação.

\section{Abstract}

Given that Job $14.13-17$ is believed to have been written as early as in the 5 th century $\mathrm{BC}$, we herein analyze the historical, economic, social, and religious context in which it was written, as well as its implications on the life of the people of Israel and the theological meaning of this piece of poetry. We also try to determine what motivated Job to hide himself in Sheol for a set time, until YHWH's wrath ceased, so that he could be once again remembered by YHWH. 
The conception of the retribution doctrine of that time was incompatible with the suffering of the righteous and faithful, victimized by the social crisis that increasingly worsened the situation of the poor. The spiritualized upper class responded to Word of YHWH, who preached the love for the poor. This study points out that the ancient practice of lectio divina should be reestablished in the present, provided that the text is allowed to exceed our own thoughts, being able to touch us both personally and communally for a response to the Divine word, through a Christian attitude in the face of human suffering.

Keywords: Book of Job; Redemption; Reconciliation; Salvation.

\section{Introdução}

Lemos, meditamos e na oração somos chamados a dar uma resposta à Palavra de Deus. $\mathrm{O}$ dom divino nos permite olhar a realidade e perguntar: Que conversão da mente, do coração e da vida o Senhor nos pede em Jó 14,13-17? Qual o sentido do desejo de Jó, manifestado no poema, de que o Senhor o esconda no sheol? A tradição do antigo Israel era de que o sofrimento e a miséria eram causados pelo pecado do homem. No entanto, Jó subverte o ensinamento da doutrina da retribuição. Qual a intenção do autor com esta polêmica? Vamos buscar a resposta a partir do contexto histórico-social da redação da poesia.

\section{O contexto histórico-social da redação de Jó 14,13-17}

Diante das argumentações colocadas pelos estudiosos do tema, concordamos que a redação da poesia é pós-exílica, do século V a. C. São compatíveis com o período: 1) a crítica do autor à doutrina da retribuição, quando a nação israelita testemunhava seu fracasso como entidade político-religiosa, acreditando que YHWH a abandonara injustamente ${ }^{1}$; 2) a estrutura urbana relatada no diálogo, com quadras públicas e portões (cf. Jó 5,4; 29,7; 31,21), onde ocorriam os acordos jurídicos e negócios públicos, evidência de uma sociedade agrícola e não nômade; 3 ) cumprimento das exigências da Aliança de culto exclusivo a YHWH e respeito ao próximo ${ }^{2}$.

\footnotetext{
${ }^{1}$ Cf. MORLA, V. Job 1-28, Bilbao: Desclee De Brouwer, 2007, pp. 12-13.

${ }^{2}$ Cf. COOGAN, M. D. "The Social Worlds of The Book of Job". In: Schloen, J. David (ed.), Exploring The Longue Durée 8: Essays in Honor of Lawrence E. Stager. Winona Lake: Eisenbrauns, 2009, pp. 77-81.
} 
Nesta época, os exilados puderam retornar da Babilônia. Ciro, rei da Pérsia, dominador tolerante, permitiu a reinserção dos exilados e a reconstrução do Templo de Jerusalém. Israel procurava se organizar e reafirmar sua identidade nacional, com a atuação de Esdras e Neemias e dos profetas Ageu, Zacarias e Malaquias. Este último reporta como uma época de desordens, com sacerdotes que não exerciam o cargo de forma devida, leigos acusados de leviandade com a religião e a prática de matrimônios com estrangeiros.

Foi também uma época de crise econômica (cf. 2Rs 4,1; Am 2,6; Is 50,1) em que: 1) a reconstrução das muralhas de Jerusalém, empreendida por Neemias, se tornou enorme e pesado fardo para o povo, obrigado a trabalhar na obra, além da própria atividade; 2) a reforma de Dario, que estipulava o pagamento de tributos em moeda de prata, exigia um excedente de produção; 3) a questão climática podia ameaçar o êxito da produção agrícola. Os pequenos agricultores, que plantavam para a própria subsistência, não conseguiam produzir o suficiente para pagar os impostos e sobreviver.

Os pobres não tinham como pagar suas dívidas e penhoravam a propriedade, a si próprios e a família, terminando todos vendidos como escravos para estrangeiros. Para Neemias, a decadência da cidade era fruto do contato com os estrangeiros e, por isso, adotou medida política segregacionista que se converteu no fundamento da nova Jerusalém. O casamento com estrangeiros passou a ser uma transgressão à Lei e o motivo das desventuras de Jerusalém (cf. Ne 13,23ss). O capital estrangeiro foi expulso de Jerusalém e o poder sadoquita foi quebrado. Foram retomados o pagamento dos dízimos ao Templo, a observância do sábado e a determinação do oferecimento ao Templo de tudo que era devido a YHWH. Os que não concordaram com as medidas exilaram-se na Samaria. ${ }^{3}$

O livro de Neemias relata o protesto que o povo apresentou ao governador contra os nִרים, nobres, e os magistrados (cf. Ne 5,7). Queixava-se de não colher o suficiente para comer e sobrar para plantar nova safra, vender e obter dinheiro para pagar os impostos. A classe alta tirava partido da situação enriquecendo cada vez mais com o beneficio do direito de crédito sobre os endividados. Neemias repreendeu os aristocratas e impôs o perdão das dívidas e a devolução dos bens e escravos penhorados, com base na tradição das antigas isenções extraordinárias (cf. Ne 5,6-13).

\footnotetext{
${ }^{3}$ Cf. SACCHI, P. Historia del Judaísmo en la época del Segundo Templo. Madrid, Editorial Trotta, 2004, pp. 151-157.
} 
As medidas não foram suficientes e o povo, empobrecido, continuava a se degradar. Apresentou-se um grande desafio ético-religioso para a comunidade e a classe alta. Certamente, sabendo que YHWH ama os pobres, tiveram de dar uma resposta à palavra do Senhor. $\mathrm{O}$ estudo da estrutura do poema, sua delimitação, tradução e análise semântica ajudam na compreensão do texto como parte da resposta a YHWH.

\section{Jó 14,13-17 no contexto do livro de Jó}

O livro de Jó possui gênero literário e estrutura próprios, com seus 42 cc. distribuídos entre narrativa (prólogo e epílogo) e poesia. A estrutura poética, bipartida, está dividida em cc. 3-27.28 e cc. 29-41. O c. 3 é o primeiro discurso de Jó, de uma série de diálogos entre Jó e seus três amigos (Elifaz, Baldad e Sofar), e o c. 28 , com o discurso da Sabedoria, faz um balanço final desse debate. A primeira parte da estrutura bipartida possui três ciclos de discursos: os cc. 3-11, os cc. 12-20 e os cc. 21-27. Cada um destes ciclos começa com um discurso de Jó. No segundo ciclo, nos cc. 12-14, está um discurso de Jó em resposta à fala de Elifaz, desmascarando os amigos e se dirigindo diretamente a YHWH. Um discurso longo, formado de quatro poemas: c. 12, c. 13,1-19, c. $13,20-28$ e c. $14 .{ }^{4}$

O quarto poema (c. 14) possui 22 vv. onde se encontra Jó 14,13-17, uma unidade literária, centro de um quadro com duas molduras, uma anterior (Jó 14,1-12) e uma posterior (Jó 14,18-22). As duas molduras têm como tema a vida do homem comparada à vida da natureza. O centro do quadro (Jó 14,1317) tem temática diferente, com o autor parecendo deter-se em uma reflexão mais profunda e abandonando as comparações do homem com a natureza.

\begin{tabular}{|c|c|c|}
\hline מִי יִּּן & $13 \mathrm{a}$ & Quem dera \\
\hline 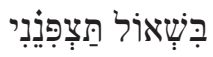 & $13 b$ & no sheol me ocultasses, \\
\hline 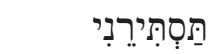 & $13 \mathrm{c}$ & me escondesses, \\
\hline עַד-שטוּב אַפְָּּ & $13 \mathrm{~d}$ & até desistires de tua ira? \\
\hline תְָּׁׁית לִי חק & $13 \mathrm{e}$ & Me fixasses um tempo, \\
\hline
\end{tabular}

${ }^{4}$ Cf. ALONSO SCHÖKEL, L. SICRE DÍAZ, J. L. Job, Comentario teológico y literario. Madrid: Ediciones Cristiandad, 2002, p. 54. 


\begin{tabular}{|c|c|c|}
\hline 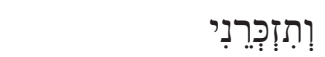 & $13 \mathrm{f}$ & e, então, recordasses de mim. \\
\hline אִם־־יָמוּת גֶּרֶר & $14 \mathrm{a}$ & Se morrer o homem, \\
\hline 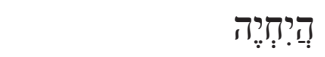 & $14 b$ & acaso viveria? \\
\hline 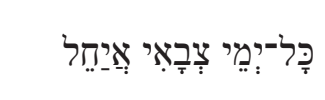 & $14 \mathrm{c}$ & $\begin{array}{l}\text { Todos os dias da minha luta eu } \\
\text { aguardaria com ansiedade }\end{array}$ \\
\hline עַד־בּּוֹא חַלְיפָתִי & $14 d$ & até chegar o meu indulto. \\
\hline תִתִקרָא & $15 \mathrm{a}$ & Convocar-me-ias, \\
\hline 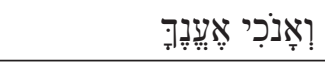 & $15 b$ & e eu te responderia: \\
\hline 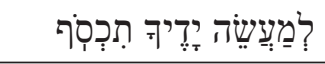 & $15 \mathrm{c}$ & da obra de tuas mãos sentirias saudade. \\
\hline 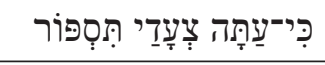 & $16 \mathrm{a}$ & Porque agora, meus passos contarias, \\
\hline לאא־תִשְׁמוֹר עַל־חַטָּאתִי & $16 b$ & não vigiarias sobre meu pecado; \\
\hline 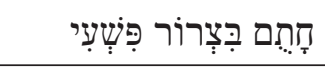 & $17 \mathrm{a}$ & selada no seixo minha transgressão, \\
\hline 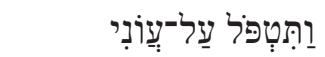 & $17 \mathrm{~b}$ & branquearias minha iniquidade. \\
\hline
\end{tabular}

Jó 14,13-17 apresenta verbos e substantivos marcados, em sua maioria, pelo uso de partículas e sufixos ligados à primeira pessoa comum singular e à segunda pessoa singular masculino, indicando predominância de uma reflexão sobre a identidade pessoal no contexto de indagação com a divindade.

A mudança de temática e o uso da expressão idiomática ’ִ̣n, introduzindo um desejo incompatível com a constatação do contido na moldura anterior ao poema, sobre a transitoriedade da vida, evidenciam a unidade literária, cujo esquema abaixo ajuda na compreensão do seu significado teológico. 
13a - um desejo

13b-13f - YHWH $\left\{\begin{array}{l}\left.\begin{array}{l}\text { ocultar - sheol } \\ \text { esconder - }\end{array}\right\} \text { um lugar } \\ \text { até desistir - } \\ \text { fixar - tempo determinado } \\ \text { recordar - espera (temporal) }\end{array}\right\}$ um tempo
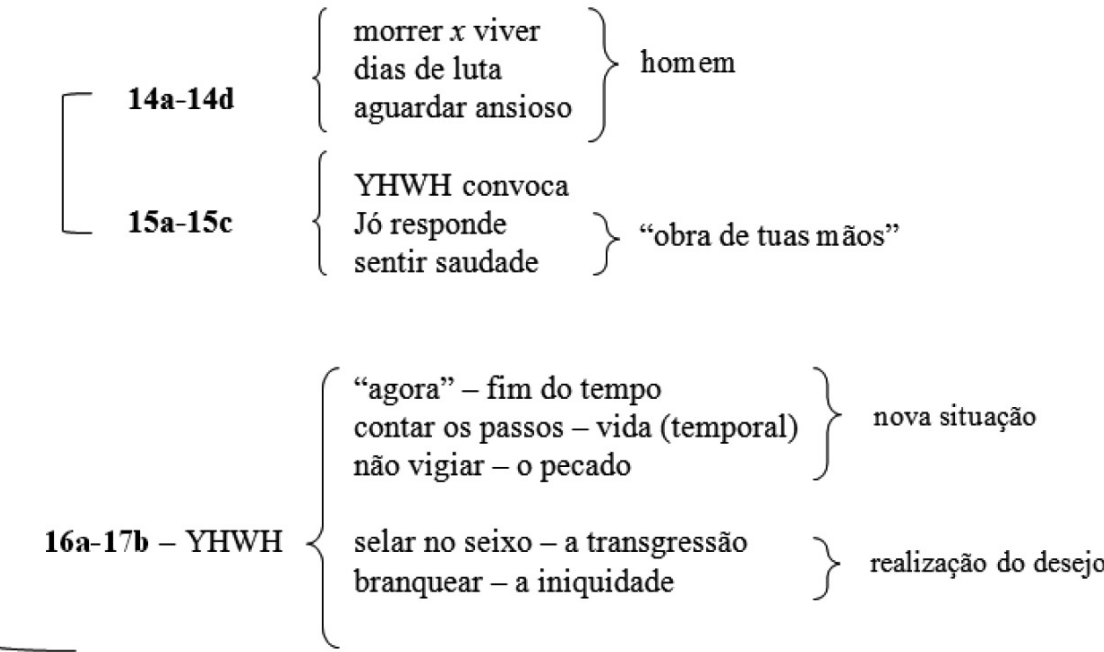

\section{Significado teológico de Jó 14,13-17}

Jó deseja esconder-se no sheol, um desejo paradoxal, pois quer ser escondido de YHWH pelo próprio YHWH, de quem ninguém se esconde. ${ }^{5} \mathrm{O}$ desejo

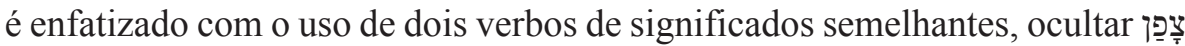
e esconder סֵַָ. O povo de Israel não tinha condições de lutar contra o império persa e os altos impostos cobrados, mas esconder-se no sheol não fazia sentido para eles, que valorizavam a vida, considerando que a mesma deveria ser vivida plenamente, com o desfrute dos recursos da criação, numa vida longa,

\footnotetext{
${ }^{5}$ Uma ironia do autor (cf. SEOW, C.-L.. "Hope in two keys: Musical Impact and the Poetics of Job 14”. In: Congress Volume Ljubljana [2007], pp. 495-510).
} 
com saúde, felicidade, prosperidade e muitos descendentes. ${ }^{6}$ Morrer significa ir para o sheol, de onde não há retorno, longe de $\mathrm{YHWH}$, de todos e de tudo (cf. S1 88,6). E, por isso, temendo não sobreviver à ira divina ${ }^{7}$, Jó quer um tempo pin para que YHWH vá dele se recordar זָ e, assim, possa voltar.

A pergunta retórica "Se morrer o homem, acaso viveria?" torna a argumentação eloquente e traz a questão do limite da vida dado por YHWH, Senhor da vida e da morte. Jó, em seu sofrimento, não desfruta de uma vida plena. O uso do verbo יָָָל "aguardar", mostra sua esperança durante seus dias de luta. $\mathrm{O}$ verbo na forma piel dá o sentido de uma espera ansiosa, até chegar

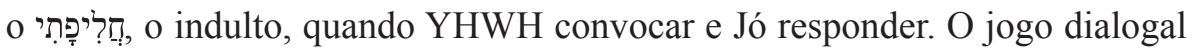

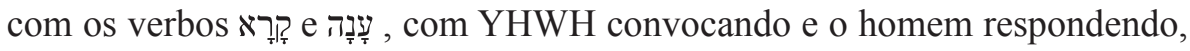
evidencia o desejo da relação. ${ }^{8} \mathrm{O}$ homem precisa de YHWH e YHWH precisa do homem. ${ }^{9}$

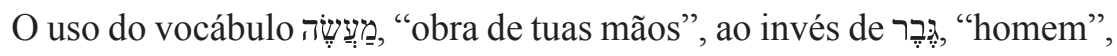
parece realçar o fato de o homem ser um "feito divino" e, como tal, estar nas

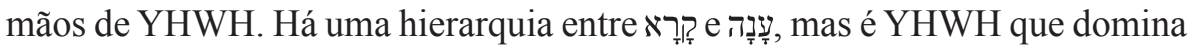

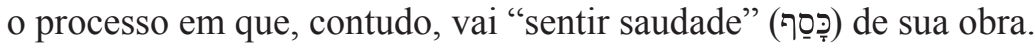

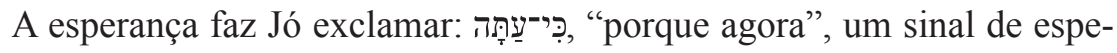
rança de um novo tempo, um futuro de felicidade ${ }^{10}$, no qual YHWH vai contar os צֵַ passos de Jó, como pai amoroso que guia os passos do filho para que não caia. ${ }^{11}$ Há uma busca pela interação e relação, equilibradas, entre

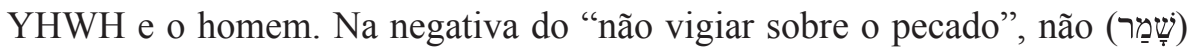
sobre o (חָטָָאת), YHWH oferece esperança de transformação, possibilidade de

${ }^{6}$ Cf. MARTIN-ACHARD, R. Da Morte à Ressurreição segundo o Antigo Testamento. São Paulo: Editora Academia Cristã Ltda, 2005, pp. 20-21.

${ }^{7}$ A questão para Jó é saber se verá o fim da ira de YHWH e terá seu destino mudado ou se será esquecido por YHWH no sheol (cf. SCHONOCKS, J., "The Hope for Ressurrection in the Book of Job". In: The Septuaginta and Messianism. Leuven: M. A. Knibb [2006], p. 291-292). 8 "Ouvir" e "responder" constitui a natureza própria do ser humano aberto ao diálogo com o divino (cf. Is 50,4s) (cf. WOLFF, H. W. Antropologia do Antigo Testamento. São Paulo: Hagnos, 2008 p. 131).

${ }^{9}$ Cf. PINKER, A. “Job's Perspectives on Death”. In: Jewish Bible Quarterly 35 (2007), pp. 73-85. ${ }^{10} \mathrm{O}$ momento de sair do sheol é o momento de viver uma vida plena, livre de mesquinhas e desapiedadas perseguições divinas (cf. Jó 14,16-17) (cf. SCHWIENHORST-SCHÖNBERGER, L. Um caminho através do sofrimento, O Livro de Jó. São Paulo: Paulinas, 2011, pp. 70-72).

${ }^{11}$ Jó se submete, reconhecendo que tem seus passos contabilizados por YHWH (cf. Jó 14,16a), e mesmo que algumas vezes imagine que YHWH possa ser seu inimigo, vive no mundo criado por YHWH e, a cada passo vê mais claramente para além dessa inimizade (cf. TERRIEN. S., Job: Poet of Existence. Oregon: Wipf and Stock Publishers, 2004, p.132). 
uma vida de justiça para todos. Com sua misericórdia, YHWH vai "selar" (



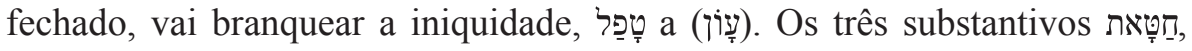

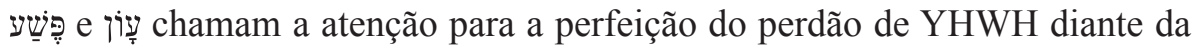
condição humana.

Em seguida, seguimos inteiramente o estudo de Rainer Albertz ${ }^{12}$ para explicar a resposta dada pela classe alta à palavra do amor divino misericordioso que redime, reconcilia e salva.

\section{A solidariedade para com o irmão desafortunado}

A crise dividiu a classe alta em uma resposta pastoral da classe alta espiritualizada, também solidária, contra a postura sedutora dos ímpios. A classe espiritualizada solidária desenvolveu um trabalho pastoral, mantendo as obrigações de misericórdia com os irmãos desventurados. Internamente, protegiam os membros do próprio grupo, sujeitos também às adversidades do clima e da política. Externamente, trabalhavam contra a postura sedutora dos ímpios. Nas escolas, faziam campanhas para neutralizar a influência egoísta, utilizando uma série de sentenças curtas na alfabetização. Pretendiam fixar nos jovens as duas alternativas, a piedade e a impiedade, com a qual teriam que conviver socialmente e fazer escolhas. Apresentavam exortações com a relação entre religiosidade e atitude ética. Os ditos repetiam inúmeras vezes o quão mal é o ímpio, e o destino que o espera. Na celebração litúrgica, propagavam a atitude solidária mostrando que sem ela a comunidade estava ameaçada. Pretendiam fixar a conduta do ouvinte à lei divina, em favor da partilha fraterna, evitando que os egoístas fossem imitados. Os solidários percebiam ser o verdadeiro Israel e cuidavam da comunidade.

O drama de Jó 14,13-17 é o drama da classe alta solidária. Na narrativa,

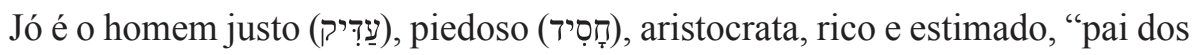
pobres", aquele que liberta o pobre do jugo dos ímpios com sua misericórdia. No contexto das leis e tradições judaicas, Jó representa o aristocrata que tem escravos e meeiros, mas é humano e misericordioso. O autor concorda que há uma ordem harmoniosa no mundo criado por YHWH, mas nele existem forças que se opõem. O sofrimento nem sempre é resultado de pecado nem desejo de

${ }^{12}$ Cf. ALBERTZ, R. Historia de la religión de Israel em tiempos del Antiguo Testamento. V.1. Madrid: Editorial Trota, 1999, pp. 661-708. 
Deus. No entanto, o ímpio mantinha a situação que justificava seu egoísmo, sentindo-se ainda digno da bênção divina. O pobre era considerado infiel e pecador, devendo conformar-se com seu sofrimento.

A expressão poética lembra que YHWH com sua misericórdia abre um novo horizonte relacional com o ser humano. A caiação espessa é dada à parede para que adquira boa aparência, uma imagem da misericórdia divina que perdoa, mas não esquece nossos pecados. Perdoar a dívida do pobre significava atender ao desejo divino, incluí-lo novamente no mercado, tornando-o apto a consumir e ajudar a impulsionar a economia, trazendo riqueza para toda a comunidade. Não há sentido em um Senhor da Criação déspota e caprichoso, que não se preocupa com o ser humano. Com o sofrimento o israelita se sentia como se estivesse próximo de estar morto, quase no sheol. O texto exclama: “Quem dera!". A fé em YHWH e o desejo de um mundo melhor exigia uma reflexão.

\section{Conclusão}

A Bíblia é a palavra de Deus para todas as épocas. A crise em Judá serviu para o autor do livro de Jó fazer uma reflexão sobre o destino do homem, o sofrimento e a realidade em que vivia. Jó não perde a fé e a esperança de um mundo mais justo. O pecado é inerente ao homem, mas YHWH oferece sempre uma saída para o pecador (cf. Jó 14,13-17), que tem livre arbítrio nas escolhas que faz (cf. Jó 8,4).

No mundo hodierno prospera o consumismo exacerbado ao lado da Teologia da Prosperidade, com seu sistema de trocas com Deus, onde poucos têm muito e muitos têm tão pouco que vivem no vale da fome, da doença e da miséria. Portanto, a Palavra de Deus pede uma resposta urgente de todos em prol de um mundo melhor e mais justo.

Jó 14,13-17 se mostra atual e de acordo com o afirmado na GaudiumEtSpes: "as alegrias e as esperanças, as tristezas e as angústias dos homens de hoje, sobretudo dos pobres e dos que sofrem, são também as alegrias e as esperanças, as tristezas e as angústias dos discípulos de Cristo". Como os aristocratas da classe alta espiritualizada, o cristão de hoje pode responder à palavra divina procurando transformar o mundo, minimizando o sofrimento e aproximando-se de Deus, que em sua misericórdia redime, reconcilia e salva. 


\section{Referências bibliográficas}

ALBERTZ, R. Historia de la religión de Israel em tiempos del Antiguo Testamento. Madrid: Editorial Trota, 1999.

ALONSO SCHÖKEL, L. Dicionário Bíblico Hebraico-Português. São Paulo: Paulus, 2010.

ALONSO SCHÖKEL, L., SICRE DÍAZ, J. L. Job, Comentario Teológico y Literario. Madrid: Ediciones Cristiandad, 2002.

ANDERSEN, F. I. Job. Nottingham: Inter-Varsity Press, 2008.

BEZUIDENHOUT, L.C. "A Context to Frame the Book of Job". In: Old Testament Essays, 9 (1996), pp. 9-19.

BÍBLIA DE JERUSALÉM. São Paulo: Paulus, 2004.

BÍBLIA SACRA UTRIUSQUE TESTAMENTI HEBRAICA ET GRAECA. Stuttgart, Deutsche: Bibelgesellschaft, 1994.

BOTTERWECK, G. J., RINGGREN, H., FABRY, H. -J. (org.), TDOT, Michigan: Eerdmans Publishing Co., V. I-XV, 1980-2006.

CLINES, J. A. D. Job 1-20. Nashville: Thomas Nelson, 1989.

COOGAN, M. D. "The Social Worlds of The Book of Job". In: SCHLOEN, J. D. (ed.), Exploring The Longue Durée 8: Essays in Honor of Lawrence E. Stager. Winona Lake: Eisenbraruns, 2009, pp. 77-81.

COSTA, F. L. G. "O livro de Jó: uma catequese para um povo fracassado em sua esperança”. In: Revista de Cultura Teológica 19 (2011), pp. 129-147.

DONNER, H. História de Israel e dos povos vizinhos, V. 2. São Leopoldo: Editora Sinodal, 2006.

FINKELSTEIN, I., SILBERMAN, N. A. A Bíblia não tinha razão. São Paulo: A Girafa, 2005.

FRANCISCO, E. F. Manual da Bíblia Hebraica. São Paulo: Vida Nova, 2003.


Interpreter's Dictionary of the Bible, V.1. New York: Abingdon Press, 1962, pp. 787-788.

GESENIUS, W. Gesenius'Hebrew Grammar. E. Kautzsch (ed.). Mineola, New York, Dover Publications, Inc, 2006. 
GIRARD, R. A rota antiga dos homens perversos. São Paulo: Paulus, 2009.

GORDIS, R. The Book Of Job, Commentary New Translation And Special Studies. New York: JTS Press, 1978.

GUNNEWEG, A. H. J. História de Israel. São Paulo: Loyola, 2005.

HARRIS, R. L.,ARCHER, G. L. Jr. WALTKE, B.K.(org.). Dicionário Internacional de Teologia do Antigo Testamento. São Paulo: Vida Nova, 2008.

HARTLEY, J. E. The Book of Job. Michigan: Eerdmans Publishing Co., 1988.

HO, E. “Job's Antecipation of Death in Job 42:6". PEGLMBS 27 (2007), pp. 31-45.

HOFFMAN, Y. "Ancient Near Eastern Literary Conventions and the Restoration of the Book of Job". In: Zeitschrift für die alttestamentliche Wissenschaft, 103 (1991), pp. 399-411.

HOFFMAN, Y. Blemished Perfection, The Book of Job in Context. Sheffield: Sheffield Academic Pres, 1996.

LASINE, Stuart. "Job: The Victim of His People (Reviews)". In: Hebrew Studies 32 (1991), pp.92-103.

MAIER, J. Entre os dois Testamentos. São Paulo: Loyola, 2005.

MARTIN-ACHARD, R. Da Morte à Ressurreição segundo o Antigo Testamento. São Paulo: Editora Academia Cristã Ltda, 2005.

MIDDlEMAS, J., CLINES, D. J. A., HOLT, E. K. (org). The Centre and the Periphery, A European Tribute to Walter Brueggemann. Sheffield: Sheffield Phoenix Press, 2010.

MORLA, V. Job 1-28. Bilbao: Desclée De Brouwe, 2007.

NEWSOM, C. A. The Book of Job, A Contest of Moral Imaginations. New York: Oxford, 2003.

PATRICK, J. E. "The Fourfold Structure of Job: Variations on a Theme". In: VT 55 (2005), pp. 185-206.

PINKER, A. “Job's Perspectives on Death". In: Jewish Bible Quarterly 35 (2007), p. 73-85.

POPE, M. H. Job, a New Translation with Commentary. New York: Double Day Company, 1973.

ROPER, L. A. "The Social Context Of The Book Of Job". VeE, 26 (2005), pp. 756-772. 
SACCHI, P. Historia del Judaísmo en la época del Segundo Templo. Madrid: Editorial Trotta, 2004.

SCHONOCKS, J. "The Hope For Ressurrection in The Book Of Job". In: The Septuaginta and Messianism. Leuven: M. A. Knibb, 2006, pp. 292-299.

SCHWINHORST-SCHÖNENBERBER, L. Olivro de Jó. São Paulo: Paulinas, 2011.

SEOW, C. L. "Poetic Closure in Job: The First Cycle". JSOT, 34 (2010), pp. 433-446.

, "Hope in two keys: Musical Impact And The Poetics Of Job 14". Congress Volume Ljubljana, (2007), pp. 495-510.

TERNAY, H. O livro de Jó. Da provação à conversão, um longo processo. Petrópolis: Vozes, 2001.

TERRIEN, S. Jó. São Paulo: Paulus, 1994.

TERRIEN, S. Job: Poet of Existence. Oregon: Wipf and Stock Publishers, 2004.

VANGEMEREN, W. A. (org.). Novo Dicionário Internacional de Teologia e Exegese do Antigo Testamento. São Paulo: Editora Cultura Cristã, 2011.

VICCHIO, S. J. Job in the Ancient World, V. 1. Eugene:Wipf and Stock Publishers, 2006.

WATERS, L. J. "Missio Dei in the Book of Job”. BSac 166 (2009), pp. 19-35

WEISER, A. Giobbe. Brescia: Paideia Editrice, 1975.

WOLF, H. W. Antropologia do Antigo Testamento. São Paulo:Hagnos, 2008.

Ednéa Martins Ornella Mestre em Teologia Bíblica - PUC-Rio

Rio de Janeiro / RJ - Brasil

E-mail: edneaornella@investik.com.br

Recebido em: 01/06/13

Aprovado em: 20/05/14 